\title{
Research
}

\section{A pharmacy medication alert system based on renal function in older patients}

\begin{abstract}
\section{Background}

Patients with diabetes or cardiovascular disease are at risk of reduced renal function and frequently use drugs that interact with renal function. GPs monitor renal function in these patients. Computerised prescription systems produce alerts in patients labelled as having chronic kidney disease, but alerts are often ignored. If pharmacists use a pharmacy medication alert system (PMAS) based on renal function, they can provide the GP with therapeutic advice to optimise the medication. The extent of this advice and the feasibility in the clinical context are unknown.
\end{abstract}

\section{Aim}

To assess the therapeutic advice formulated by pharmacists with help of a PMAS based on the renal function of patients aged $\geq 70$ years with diabetes or cardiovascular disease.

\section{Design and setting}

Observational study in primary health care in the Netherlands.

\section{Method}

GPs provided pharmacists with the renal function of older patients with diabetes or cardiovascular disease who were using target drugs, that is, drugs requiring therapeutic advice in patients with reduced renal function. With the help of a PMAS, pharmacists assessed the actual medication. The GP weighed the advice in relation to the clinical context of the individual patient.

\section{Results}

Six hundred and fifty patients were prescribed 1333 target drugs. Pharmacists formulated 143 therapeutic recommendations $11 \%$ of target drugs) concerning 89 patients $(13.7 \%$ of study population). In 71 recommendations in 52 patients ( $8.0 \%$ of study population), the GP agreed immediately.

\section{Conclusion}

The use of a PMAS resulted in therapeutic advice in $11 \%$ of the target drugs. After weighing the clinical context, the GP agreed with half of the advice.

\section{Keywords}

aged; medication alert systems; medication errors; primary health care; renal insufficiency.

\section{INTRODUCTION}

Chronic kidney disease (CKD) is a growing health problem, with a prevalence from $4.9 \%$ in general practice in the UK to up to $13 \%$ in the US population. ${ }^{1-3}$ The medical consequences of CKD are not only the risk of end-stage renal disease and cardiovascular morbidity, but also an increased risk of adverse drug events and medication-related hospital admissions. 4,5

When renal function is reduced, the dosage of drugs that depend on renal excretion should be adjusted and nephrotoxic drugs should be avoided. ${ }^{6-8}$ Patients with diabetes and cardiovascular disease have an augmented risk of CKD and frequently use renally cleared drugs. ${ }^{1,9}$ Medication alerts systems warn prescribers of medication that can interact with impaired renal function, but these alerts are often ignored. ${ }^{10-13} \mathrm{~A}$ medication alert system that weighs the actual renal function of the patient could help to reduce medication errors. ${ }^{14-16}$

This observational study assessed the therapeutic advice formulated by the pharmacist with help of a medication alert system based on the renal function of patients aged $\geq 70$ years with diabetes or cardiovascular disease.

AFJ Geerts, PharmD, researcher, Division of Pharmacoepidemiology and Clinical Pharmacology, Utrecht Institute for Pharmaceutical Sciences, Faculty of Science, Utrecht University and Department of Clinical Pharmacy, University Medical Centre Utrecht, Utrecht, the Netherlands. ND Scherpbier-de Haan, MD, GP, researcher; TMJW van der Sterren, MD, GP; C van Weel, PhD, $M D, F R C G P, G P$ and professor in general practice; WJC de Grauw, PhD, MD, GP, Department of Primary and Community Care; GMM Vervoort, MD internist-nephrologist, Department of Nephrology, Radboud University Nijmegen Medical Centre, Nijmegen, the Netherlands. FHP De Koning, PharmD, PhD, Division of Pharmacoepidemiology and Clinical Pharmacology, Utrecht Institute for Pharmaceutical Sciences, Faculty of Science, Utrecht University, Utrecht, the Netherlands. PAGM De Smet, PharmD, PhD, professor of quality of the pharmaceutical patient care, Departments of
METHOD

\section{Setting and study population}

The study was conducted in Arnhem, a city in the East of the Netherlands with nearly 148 000 inhabitants. Seven GPs, belonging to the same pharmacotherapy audit meeting group, participated in the study. Five pharmacists who worked in close collaboration with this group selected the patients in their pharmacy computer system. Patients aged $\geq 70$ years in the care of the participating GPs were eligible if they were on GP-prescribed maintenance therapy of blood-glucose-lowering or cardiovascular drugs (for example, digoxin, diuretics, or inhibitors of the renin-angiotensin system [RAS], including angiotensin-converting enzyme [ACE] inhibitors and angiotensin II receptor blockers [ARBs]]. Patients also used at least one 'target drug' on the inclusion date of 4 January 2010. 'Target drugs' were defined as drugs requiring therapeutic advice in patients with decreased renal function considering the Dutch dosing guideline for impaired renal function. ${ }^{17}$ Patients with an estimated glomerular filtration rate (eGFR) $<10 \mathrm{ml} / \mathrm{min} / 1.73 \mathrm{~m}^{2}$ were excluded (Figure 1).

Clinical Pharmacy and IQ Healthcare, Radboud University Nijmegen Medical Centre, Nijmegen, the Netherlands.

\section{Address for correspondence}

Arjen FJ Geerts, Division of Pharmacoepidemiology and Clinical Pharmacology, Utrecht Institute for Pharmaceutical Sciences, Faculty of Science, Utrecht University, PO Box 80 082, 3508 TB Utrecht, the Netherlands.

E-mail: a.f.j.geertsquu.nl

Submitted: 4 January 2012; Editor's response: 17 January 2012; final acceptance: 2 February 2012

\section{(CBritish Journal of General Practice}

This is the full-length article (published online 30 Jul 2012) of an abridged version published in print. Cite this article as: Br J Gen Pract 2012; DOI: 10.3399/bjgp12X653561. 


\section{How this fits in \\ Patients who use drugs that interact with impaired renal function require monitoring of renal function to avoid medication errors. In daily practice, the adjustment of medication in relation to renal function does not always get the attention that it deserves. The use of a pharmacy medication alert system based on renal function may be of additional value. In this study, the use of such a system resulted in therapeutic advice concerning $11 \%$ of the drugs that interact with renal function, and the GP agreed with half of the therapeutic advice.}

The GPs already used a computerised medication monitoring system. This system generated an alert when the GP prescribed a target drug in patients labelled as having CKD, but it could not consider the eGFR level.

The use of drug dispensing data and laboratory test results in this study complied with Dutch privacy regulations.

\section{Renal function monitoring}

Actual eGFR was defined as an eGFR value measured within the last 12 months. If an actual eGFR was unknown, the GP requested the patient to undergo a blood test for renal function. The laboratory provided serum creatinine and an eGFR $\left(\mathrm{ml} / \mathrm{min} / 1.73 \mathrm{~m}^{2}\right)$ calculated by the normalised four-variable Modification of Diet in Renal Disease (MDRD). ${ }^{18}$ Serum creatinine was measured enzymatically (Modular.

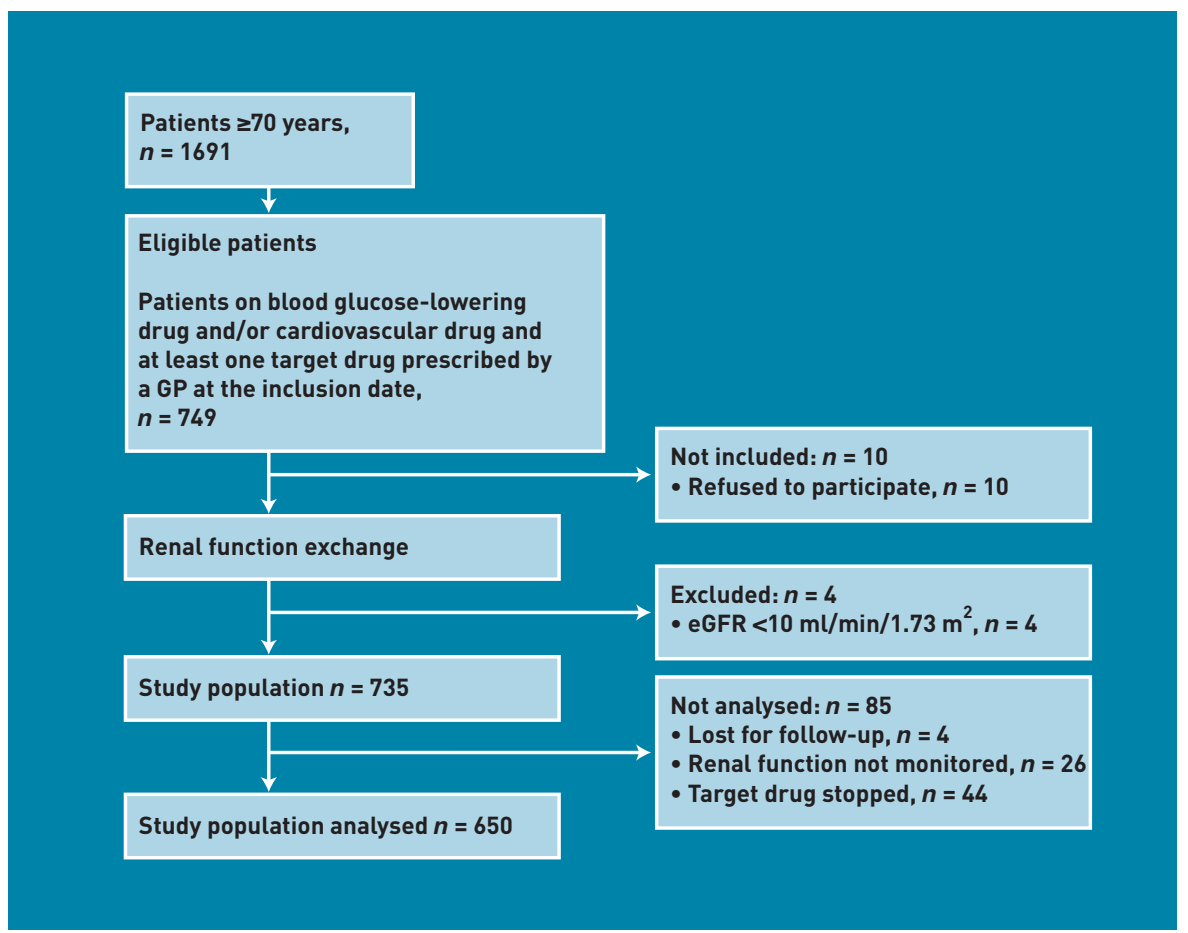

Roche diagnostics) and was IDMS (isotope dilution mass spectrometry) calibrated. The actual values of eGFR data were provided to determine drug-specific risk.

\section{Assessment of renal function alerts}

In this study, the pharmacists used a pharmacy medication alert system (PMAS) built by one of the authors in a Microsoft ${ }^{\circledR}$ Access ${ }^{\circledR}$ database. The system, which was an addition to the current pharmacy computer system, assessed the medication in relation to the reported eGFR and provided an alert for target drugs according to the Dutch guidelines for drug administration in reduced renal function. ${ }^{17}$ These guidelines include drug-specific cut-off values for eGFR, accompanied by a therapyadjustment advice.

After receiving a data file from the GP with the eGFR of the included patients, the pharmacists linked the eGFR in the PMAS. Simultaneously, the patient's actual medication was electronically imported from the usual pharmacy computer system into the PMAS. An alert was generated to stipulate action if the eGFR was lower than the cut-off value of the target drug (Table 1). The software could not correct for invalid dose or dose interval, so the pharmacist assessed the alerts for these aspects based on the guideline recommendations presented in a text box. The pharmacist formulated therapeutic advice for either dosage adjustment, to stop the drug, or to substitute it by a non-contraindicated drug. Once a week, the pharmacist communicated the therapeutic advice to the GP by a list. The GP evaluated the therapeutic advice in relation to the clinical context of each individual patient, and responded with agreement or disagreement. Predefined reasons for disagreement could be checked on the list and the GP was asked to give supplementary comments in a free-text box. The list was returned to the pharmacist.

\section{Outcome}

The outcome of the study was the frequency of therapeutic advice formulated by the pharmacist (expressed as a proportion of the total number of target drugs). The management of the therapeutic advice by the GP was also studied.

\section{Statistical analysis}

All relevant patient data were entered into a Microsoft Access 2003 database and further analysed with SPSS Statistics (version 17.0) for descriptive statistics (mean, frequency, range). 


\section{Table 1. Predefined cut-off values top 10 target drugs with truncated} guideline advice

\begin{tabular}{llcl} 
& \multicolumn{3}{c}{ Cut-off values, } \\
Therapeutic group & Drug name & $\mathbf{m l} / \mathbf{m i n}$ & Guideline advice \\
\hline Blood-glucose-lowering drugs & Metformin & $30-50$ & Initial dose $2 \times 500 \mathrm{mg}$ \\
& & $<30$ & Contraindicated \\
\cline { 2 - 4 } & Glimepiride & $10-50$ & Initial dose $50 \%$ \\
\hline Cardiac glycosides (digoxin) & Digoxin & $10-50$ & Initial dose $50 \%$ \\
\hline Low-ceiling diuretics, thiazides & Hydrochlorothiazide & $30-50$ & Initial dose $12.5 \mathrm{mg}$ \\
\hline High-ceiling diuretics & & $<30$ & Contraindicated \\
\hline Potassium-sparing diuretics & Furosemide & $10-30$ & Dose higher \\
\hline Diuretics combinations & Spironolactone & $10-50$ & Monitor potassium \\
\cline { 2 - 4 } & Amiloride & $30-50$ & Monitor potassium \\
& & $<30$ & Contraindicated \\
\hline Beta-blockers & Triamterene & $30-50$ & Dose $50 \%$, monitor potassium \\
\cline { 2 - 4 } & & $<30$ & Contraindicated \\
\hline Angiotensin-converting enzyme inhibitors & Enalizide & $<30$ & Contraindicated \\
\cline { 2 - 4 } & Sotalol & $30-50$ & Max dose $160 \mathrm{mg} /$ day \\
\hline
\end{tabular}

\section{Table 2. Characteristics of the analysed study population}

\begin{tabular}{|c|c|c|}
\hline Characteristic & $n$ & $\%$ \\
\hline Patients & 650 & 100.0 \\
\hline Female & 433 & 66.6 \\
\hline \multirow[t]{2}{*}{ Target drugs } & 1333 & \\
\hline & Mean & SD (range) \\
\hline Age, years & 81 & $6.7(70-101)$ \\
\hline eGFR, $\mathrm{ml} / \mathrm{min} / 1.73 \mathrm{~m}^{2}$ & 63.3 & $17.0(13->95)$ \\
\hline Number of drugs & 5.8 & $2.8(1-17)$ \\
\hline Number of target drugs & 2 & $1.1(1-7)$ \\
\hline Patients prescribed target drugs by therapeutic group & $n$ & $\%$ \\
\hline Blood glucose-lowering drugs & 156 & 24.0 \\
\hline Cardiac glycosides digoxin & 73 & 11.2 \\
\hline Low-ceiling diuretics thiazides & 259 & 39.8 \\
\hline High-ceiling diuretics & 164 & 25.2 \\
\hline Potassium sparing diuretics & 49 & 7.5 \\
\hline Diuretics combinations & 46 & 7.1 \\
\hline Beta-blocker sotalol & 33 & 5.1 \\
\hline Beta-blockers atenolol/bisoprolol & 31 & 4.8 \\
\hline RAS inhibitors & 224 & 5.1 \\
\hline
\end{tabular}

\section{RESULTS}

On the inclusion date, 650 patients were included and analysed (Figure 1). These patients were prescribed 1333 target drugs (Table 2). An actual eGFR had been determined in $78.5 \%(n=510)$ of the patients (range per GP $=66-89 \%$ ). In the remaining patients, eGFR was determined after the inclusion date.

\section{Assessment of renal function alerts}

The computer software generated 212 alerts $(15.9 \%)$ in a total of 1333 target drugs, because the eGFR was lower than the predefined cut-off value of the target drug. After the pharmacist assessed the actual medication for correct dose and dose interval, 93 alerts $(7.0 \%)$ appeared to be correct and seven alerts (0.5\%) were missing. Therefore, action to adjust therapy was considered necessary in 112 prescriptions in 74 patients $(8.4 \%$ of the target drugs, $11.4 \%$ of the patients). Additionally, pharmacists gave advice in 31 prescriptions of target drugs, even though the eGFR was just above the cut-off value. Eventually, 143 therapeutic recommendations $110.7 \%$ of the target drugs) concerning 89 patients $13.7 \%$ of analysed study population) were included for analysis of the GP responses. The drugs most frequently involved were diuretics ( $41.3 \%$ of therapeutic advice), blood-glucoselowering drugs (14.0\%), digoxin (11.2\%), and RAS inhibitors (10.5\%). Almost all prescriptions that received an alert were chronic prescriptions taken by the patient for a longer period of time.

\section{GP response to pharmacist advice}

The GP immediately agreed with 71 recommendations $149.7 \%$ of the therapeutic advice) concerning 52 patients $(8.0 \%$ of the study population). The GP most frequently disagreed with the advice on diuretics, bloodglucose-lowering drugs, digoxin, and RASinhibitors. Within each of these therapeutic groups, the GP immediately disagreed with one-third of the advice. The responses of the GPs are shown in Table 3.

\section{DISCUSSION}

\section{Summary}

The use of a PMAS based on renal function resulted in therapeutic advice for a substantial number of drugs in older patients with diabetes or cardiovascular disease. The GP immediately agreed with half of the advice. Overall, in $5 \%$ of the prescriptions, the GP agreed to rectify the prescription.

The GPs used a medication monitoring system based on the Dutch G-standard, ${ }^{17}$ the national drug database, which is used by all professional parties in Dutch health care. Despite this monitoring system, pharmacists still formulated additive therapeutic advice in $11 \%$ of the target drugs. What could be the reasons for this? First, it is known that a high number of medication alerts may cause 'alert fatigue' in the prescriber. ${ }^{10}$ In the case of repeat prescriptions in particular, alerts were ignored. The extra effort to seek a renal function and to weigh the choice and dosage of the drug may cost too much time. Second, this observation could be explained because at the time of prescription, an actual eGFR was not available in more than $20 \%$ of the patients. Finally, it is important to consider 
Table 3. GP response

\begin{tabular}{lccl} 
Response & $\boldsymbol{n}$ (total $\mathbf{N}=\mathbf{1 4 3})$ & \% & Comments \\
\hline Immediate agreement & 71 & 49.7 & 52 patients, 8\% of study population \\
\hline Postponed reaction & 20 & 14.0 & - \\
\hline GP first wants to consult specialist & 12 & 8.4 & - \\
\hline GP first wants to speak to patient & 6 & 4.2 & - \\
\hline Further monitoring biomarker(s) & 2 & 1.4 & Potassium, creatinine \\
\hline Disagreement & 38 & 26.6 & - \\
\hline No standard reason indicated & 17 & 11.9 & $\begin{array}{l}\text { No adverse reactions }(n=1), \\
\text { already low dose }(n=2)\end{array}$ \\
\hline Potassium normal & 5 & 3.5 & - \\
\hline Disease is stable & 16 & 11.2 & $\begin{array}{l}\text { Diabetes }(n=5), \text { heart failure }(n=7), \\
\text { hypertension }(n=3), \\
\text { renal function }(n=1)\end{array}$ \\
\hline Specialist is treating patient & & $\begin{array}{l}\text { Specialist was responsible for the } \\
\text { drug therapy }(G P \text { only prescribed } \\
\text { the refill prescriptions) }\end{array}$
\end{tabular}

\section{Funding}

None.

\section{Ethical approval}

Ethics approval was not required, according to the accredited Medical Research Ethics Committee Arnhem/Nijmegen (number 2008/179).

\section{Provenance}

Freely submitted; externally peer reviewed.

\section{Competing interests}

The authors have declared no competing interests.

\section{Acknowledgments}

The authors would like to thank Professor AC Egberts for his comments on the manuscript. We would very much like to thank all the pharmacists, FT Schroor, FJJM van der Leemputte, DC Sietses, F Dijkhuizen-Behr, B Klok, and the GPs MHGA van Wijk, JJ Hammink, WJ MaréeWibbelink, RM Linders, MP HuizingMientjens, MMJ Hendriks, and $M$ van Duivenboden, who participated in the study.

\section{Discuss this article}

Contribute and read comments about this article on the Discussion Forum: http://www.rcgp.org.uk/bjgp-discuss the prescribing context. The alerts concerned chronic medication that the patient may have been using for a longer period of time, with an established clinical effect and with the patient accustomed to take them. Change of drug choice under these circumstances may disrupt the flow of treatment.

The use of a PMAS reduced the number of alerts compared to the current pharmacy computer system. A more sophisticated clinical decision support system could further reduce the number of irrelevant alerts by incorporating invalid dose or doseinterval algorithms that can weigh comorbidity and other patient-related risk factors that may affect the reliability of the eGFR, ${ }^{19}$ and by linking laboratory to pharmacy data. Currently, some of these principles are already incorporated in new versions of medication monitoring systems.

\section{Strengths and limitations}

This study revealed the benefit of therapeutic advice automatically generated by a PMAS based on renal function. The clinical relevance is substantial: prescribing of target drugs to older patients with diabetes or cardiovascular disease is a daily activity in primary care, and the risk of complications related to renal function is high. ${ }^{4}$ Primary care studies on compliance to dosing guidelines in patients with CKD are rare. ${ }^{6}$ Recently, Bhardwaja et al demonstrated in a large US study of 32917 patients with an eGFR below $50 \mathrm{ml} / \mathrm{min} / 1.73 \mathrm{~m}^{2}$, that an alert system in the pharmacy can result in a reduction of medication errors from $49 \%$ to $33 \% .^{14}$

The data may not be generalisable to other settings because of the small number of participating practices, but the underlying problem of medication safety in relation to renal function and the intervention of a PMAS is of general interest.

The advice given was based on a single eGFR value obtained not more 1 year previously. This was for pragmatic reasons: the renal function of patients who are in a diabetes or hypertension control system should be monitored yearly. However, variability in serum creatinine measurements necessitates at least two creatinine measurements, ${ }^{20,21}$ and even more frequent monitoring of renal function is needed in patients who are not stable. ${ }^{22}$

\section{Comparison with existing literature}

GPs immediately agreed with half of the therapeutic advice. This is in accordance with the acceptance rate in a study in which clinical pharmacists gave therapeutic recommendations to GPs based on the medical records of 200 patients with diabetes or hypertension. ${ }^{23}$ In a hospital setting, the acceptance rate was the same: $55 \%$ of the pharmacist advice was accepted by the clinician. ${ }^{15}$

Besides the predefined reasons for disagreement, the GPs were not very explicit with their comments in the free-text box. Disagreement could be explained by a difference between the dosage guidelines and clinical practice. An example is the advice to start with low doses of RAS inhibitors to prevent adverse drug reactions, whereas current clinical practice guidelines do advise to prescribe RAS inhibitors in high doses in order to protect kidney function (with monitoring of renal function and serum potassium). ${ }^{24-26}$ Meanwhile, the advice in the Dutch dosage guidelines has been adjusted to clinical practice.

\section{Implications for research and practice}

To optimise drug prescribing in patients with decreased renal function, many steps need to be taken: systematic renal function monitoring in patients on target drugs, linking the laboratory to the pharmacy, assessment of the alerts by both pharmacist and GP, and communication with the patient on the proposed prescription change. When implementing a PMAS, all above-mentioned steps deserve attention.

A PMAS based on renal function resulted in therapeutic advice in one of every nine target drugs in older patients on bloodglucose-lowering or cardiovascular drugs. After weighing the clinical context, the GP agreed with half of the advice. Collaboration between the GP and pharmacist, using their clinical and pharmacological expertise respectively, can contribute to patient safety. 


\section{REFERENCES}

1. Coresh J, Selvin E, Stevens L, et al. Prevalence of chronic kidney disease in the United States. JAMA 2007; 298(17): 2038-2047.

2. Levey AS, Coresh J, Balk E, et al. National Kidney Foundation practice guidelines for chronic kidney disease: evaluation, classification, and stratification. Ann Intern Med 2003; 139(2): 137-147.

3. De Lusignan $S$, Chan T, Stevens P, et al. Identifying patients with chronic kidney disease from general practice computer records. Fam Pract 2005; 22(3): 234-241.

4. Leendertse AJ, Egberts ACG, Stoker LJ, et al. Frequency of and risk factors for preventable medication-related hospital admissions in the Netherlands. Arch Intern Med 2008; 168(17): 1890-1896.

5. Zhang M, Holman C, D'Arcy J, et al. Comorbidity and repeat admission to hospital for adverse drug reactions in older adults: retrospective cohort study. BMJ 2009; 338: a2752.

6. Long CL, Raebel MA, Price DW, et al. Compliance with dosing guidelines in patients with chronic kidney disease. Ann Pharmacother 2004; 38(5): 853-858.

7. Avery AJ, Dex GM, Mulvaney C, et al. Development of prescribing-safety indicators for GPs using the RAND Appropriateness Method. Br J Gen Pract 2011; DOI: 10.3399/bjgp11X588501.

8. Vidal L, Shavit M, Fraser A, et al. Systematic comparison of four sources of drug information regarding adjustment of dose for renal function. BMJ 2005 331(7511): 263

9. National Collaborating Centre for Chronic Conditions. Chronic kidney disease: national clinical guideline for early identification and management in adults in primary and secondary care. London: Royal College of Physicians, 2008. http://guidance.nice.org.uk/nicemedia/live/12069/42116/42116.pdf laccessed 3 Jul 2012).

10. Isaac T, Weissman JS, Davis RB, et al. Overrides of medication alerts in ambulatory care. Arch Intern Med 2009; 169(3): 305-311.

11. Raebel MA, Lyons EE, Chester EA, et al. Improving laboratory monitoring at initiation of drug therapy in ambulatory care: a randomized trial. Arch Intern Med 2005; 165(20): 2395-2401.

12. Van Dijk EA, Drabbe NRG, Kruijtbosch M, et al. Drug dosage adjustments according to renal function at hospital discharge. Ann Pharmacother 2006 40(12): $1254-1260$

13. Weingart SN, Toth M, Sands DZ, et al. Physicians' decisions to override computerized drug alerts in primary care. Arch Intern Med 2003; 163(21): 2625-2631.
14. Bhardwaja B, Carroll NM, Raebel MA, et al. Improving prescribing safety in patients with renal insufficiency in the ambulatory setting: the Drug Renal Alert Pharmacy (DRAP) program. Pharmacotherapy 2011; 31(4): 346-356.

15. Hassan Y, Al-Ramahi RJ, Aziz NA, et al. Impact of a renal drug dosing service on dose adjustment in hospitalized patients with chronic kidney disease. Ann Pharmacother 2009; 43(10): 1598-1605.

16. Schiff GD, Klass D, Peterson J, et al. Linking laboratory and pharmacy: opportunities for reducing errors and improving care. Arch Intern Med 2003 163(8): 893-900.

17. KNMP Royal Dutch Association for the Advancement of Pharmacy (ed.). Dutch dosing guideline for impaired renal function. The Hague: Thieme GrafiMedia, 2009.

18. Stevens LA, Nolin TD, Richardson MM, et al. Comparison of drug dosing recommendations based on measured GFR and kidney function estimating equations. Am J Kidney Dis 2009; 54(1): 33-42.

19. Stevens LA, Coresh J, Greene T, et al. Assessing kidney function: measured and estimated glomerular filtration rate. N Engl J Med 2006; 354(23): 2473-2483

20. Myers GL, Miller WG, Coresh J, et al. Recommendations for improving serum creatinine measurement: a report from the laboratory working group of the national kidney disease education program. Clin Chem 2006; 52(1): 5-18.

21. National Kidney Foundation. K/DOQI guidelines. New York, NY: NKF. http://www.kidney.org/professionals/kdoqi/guidelines.cfm laccessed 3 Jul 2012).

22. National Institute for Health and Clinical Excellence. Chronic kidney disease: early identification and management of chronic kidney disease in adults in primary and secondary care (GG23). London: NICE, 2008. http://www.nice.org.uk/nicemedia/pdf/CG073NICEGuideline.pdf laccessed 3 Jul 2012)

23. Patel HR, Pruchnicki MC, Hall LE. Assessment for chronic kidney disease service in high-risk patients at community health clinics. Ann Pharmacother 2005; 39(1): 22-27.

24. Ahmed A. Use of angiotensin-converting enzyme inhibitors in patients with heart failure and renal insufficiency: how concerned should we be by the rise in serum creatinine? J Am Geriatr Soc 2002; 50(7): 1297-1300.

25. Bakris G, Weir M. Angiotensin-converting enzyme inhibitor-associated elevations in serum creatinine: is this a cause for concern? Arch Intern Med 2000; 160(5): 685-693.

26. Brantsma AH, Bakker SJL, Hillege HL, et al. Cardiovascular and renal outcome in subjects with $\mathrm{K} / \mathrm{DOQ}$ stage 1-3 chronic kidney disease: the importance of urinary albumin excretion. Nephrol Dial Transplant 2008; 23(12): 3851-3858. 